\title{
Temporo-spatial expression of adrenomedullin and its receptors in the bovine placenta
}

\author{
Ken-Go Hayashi ${ }^{1}$, Misa Hosoe ${ }^{2}$, Ryosuke Sakumoto ${ }^{1}$ and Toru Takahashi ${ }^{1,3^{*}}$
}

\begin{abstract}
Background: Adrenomedullin (AM) is a potent vasodilator peptide and is also involved in various physiological activities. In humans and rodents, AM is found in the uteroplacental unit and may be responsible for fetal development and maintenance of placental function. This study investigated 1) the mRNA expression patterns of AM and its receptor components (calcitonin receptor-like receptor (CRLR), receptor activity modifying protein (RAMP) 2 and RAMP3) during pregnancy and 2) MRNA and protein localization of AM, CRLR and RAMPs in the bovine placentome.
\end{abstract}

Methods: For real-time quantitative RT-PCR, bovine uteroplacental tissues were collected from Day 25, 60, 100, 150, 200 and 250 of gestation and separated into uterine caruncle (CAR), intercaruncular endometrium (ICAR), extra-embryonic membranes on Day 25 and cotyledonary villous after Day 60 (EEM-COT) and intercotyledonary chorion (ICOT). In situ hybridization and immunohistochemistry was performed to investigate the cellular localization of mRNA and protein of AM, CRLR, RAMP2 and RAMP3 in the placentome on Day 56, 150 and 230 of gestation and interplacentomal tissues on Day 56 of gestation.

Results: AM mRNA was highly expressed on Day 200 in EEM-COT, CAR and ICAR. CRLR mRNA was highly expressed on Day 60 in all portions. RAMP2 mRNA was also highly expressed on Day 60 in ICOT and ICAR. In EEM-COT, mRNA expression of CRLR and RAMP2 decreased from Day 150 to 250. RAMP3 mRNA was highly expressed on Day 150 in EEM-COT, ICOT and ICAR. A distinct AM mRNA and protein signal were only found in trophoblast binucleate cells (BNCs), whereas those of CRLR, RAMP2 and RAMP3 were detected in cotyledonary villous and caruncular epithelial cells. In interplacentomal tissues, AM was detected in BNCs of fetal membrane and a small part of luminal epithelium, endothelial lineage of blood vessels and glandular epithelium of the endometrium. Distinct signals of CRLR, RAMP2 and RAMP3 were found in trophoblast cells, luminal epithelium, stroma under the epithelium, endothelial lineage of blood vessels and glandular epithelium.

Conclusions: Our results indicate that the AM system in the bovine uteroplacental unit may be activated at placentation and transition from the mid to late gestation period. Locally produced AM in the BNCs may play a crucial role in regulation of placental vascular and cellular functions during pregnancy.

\section{Background}

Ruminants have an epitheliochorial-cotyledonary placenta, which is formed at the interface between endometrial caruncles (CAR) and fetal cotyledon (COT) and especially characterizes the migration of trophoblast binucleate cells (BNCs) [1]. Both fetal and maternal components of bovine

\footnotetext{
* Correspondence: tatoru@iwate-u.ac.jp

${ }^{1}$ Animal Physiology Research Unit, Division of Animal Science, National

Institute of Agrobiological Sciences, Tsukuba 305-8602, Japan

${ }^{3}$ Present address: Cooperative Department of Veterinary Medicine, Faculty of Agriculture, Iwate University, Morioka 020-8550, Japan

Full list of author information is available at the end of the article
}

placenta develop vasculature at the first trimester of gestation, which become more elaborate structures during the course of pregnancy [2]. A variety of angiogenic and vasoactive substances released from vascular endothelial cells and placental cells is thought to regulate local vascular functions in the bovine placenta [3-6].

Adrenomedullin (AM) is a potent vasodilator peptide that was originally isolated from human phaeochromocytoma [7]. Bovine AM consists of 52 amino acids and its sequence is highly conserved with human, porcine, canine, rat and mouse AM [8]. Adrenomedullin acts through a complex of calcitonin receptor-like receptor (CRLR) and its associated

\section{Biomed Central}


receptor activity modifying proteins (RAMPs) [9]. CRLR combines with RAMP2 and RAMP3 to form AM1 receptor and AM2 receptor, respectively. In addition to potent vasodilatory effects, AM is involved in multiple physiological activities such as angiogenesis, apoptosis, inflammation, cell proliferation and endocrine secretion [10-12]. Previous studies have demonstrated that AM function is required for normal fetal growth and placental development in humans and rodents. In the human placenta, AM and CRLR are mainly expressed in syncytiotrophoblast cells and fetal membranes including amnion and extravillous cytotrophoblast cells [13-17]. In the mouse placenta, trophoblast giant cells abundantly express $A M$ mRNA [18]. Both $A M$ and RAMP3 mRNA levels in rat placenta were higher in mid than in late gestation [19]. In rats, AM antagonist treatment during early or late gestation decreased placental size, restricted fetal growth and induced deficient placental vascular formation [20,21]. AM heterozygous knockout mice had reduced fertility caused by restricted fetal growth due to a high incidence of abnormal trophoblast cell invasion followed by morphological placental defects [22].

The ruminant placenta has different structures from humans and rodents, which is characterized by noninvasive trophoblast cells that never migrate into the basement membrane of the uterine endometrial unlike the placenta of humans and rodents. Since AM plays a role in various physiological functions such as angiogenesis, tissue remodeling, hormone secretion and placental development, we expect that AM is locally produced and its receptors are also distributed in the bovine placenta. However, there is no detailed information available about the involvement of AM in feto-placental development in ruminants. The objective of this study was 1) to determine mRNA expression patterns of $A M, C R L R, R A M P 2$ and $R A M P 3$ in the bovine uteroplacental unit during pregnancy; and 2) to investigate mRNA and protein localization of AM, CRLR and RAMPs in the bovine placentome and interplacentomal tissues.

\section{Methods}

\section{Animals and sample collection}

Bovine uteroplacental tissues for quantitative real-time PCR (QPCR) were obtained from pregnant Japanese-Black cows in the institute ranch. We collected tissue samples from endometrial tissues of intercaruncular areas (ICAR), extravillous trophoblast of intercotyledonary areas (ICOT) on Day 25 to 28 (Day 25; $\mathrm{n}=4$ animals), 56 to 65 (Day 60; $\mathrm{n}=6$ animals), 100 (Day 100; $\mathrm{n}=3$ animals), 143 to 150 (Day 150; $\mathrm{n}=4$ animals), 201 to 203 (Day 200; $\mathrm{n}=4$ animals) and 245 to 259 (Day 250; $\mathrm{n}=6$ animals) and placentome on Day 60, 100, 150, 200 and 250 of gestation. The placentome were manually separated into two portions, CAR and COT. The day of artificial insemination was designated as Day 1 of gestation. Because it was difficult to isolate COT from the membranes, the extra-embryonic membrane (EEM) on Day 25 contained fetal membrane with a few villi. Collected samples were snap-frozen in liquid nitrogen and stored at $-80^{\circ} \mathrm{C}$ until RNA extraction. Bovine placentome for in situ hybridization and immunohistochemistry was collected from JapaneseBlack cows immediately after slaughter on Day 56, 150 and 230 of gestation. We also collected the interplacental tissues on Day 56 of gestation. Collected tissues were fixed in 10\% formalin $(\mathrm{v} / \mathrm{v})$, embedded in paraffin wax, and stored at $4^{\circ} \mathrm{C}$ until use. All procedures for animal experiments were carried out in accordance with guidelines approved by the Animal Ethics Committee of the National Institute of Agrobiological Sciences for the use of animals (H18-036).

\section{Quantitative real-time RT-PCR analysis}

Total RNA was extracted from each sample using ISOGEN (Nippon Gene, Tokyo, Japan) according to the manufacturer's instructions. The details of procedures for single-strand cDNA synthesis and QPCR using an Mx3000P QPCR system (Agilent Technologies, Palo Alto, CA, USA) were described previously by our colleague [23]. The primers were designed using the Primer Express computer software program (Applied Biosystems, Foster

Table 1 Details of the primers used for quantitative real-time RT-PCR analysis

\begin{tabular}{|c|c|c|c|c|}
\hline Gene name & GenBank accession number & Primer & Sequences & Position \\
\hline \multirow[t]{2}{*}{$A M$} & NM_173888 & Forward & 5'-TCTCAGCGAGATGCAACGTT-3' & $1416-1435$ \\
\hline & & Reverse & 5'-CCACAAGAGGCAACTCATCTCT-3' & $1492-1471$ \\
\hline \multirow[t]{2}{*}{$C R L R$} & NM_001102107 & Forward & 5'-TCCCAGTTCATCCATCTCTACC-3' & $1065-1086$ \\
\hline & & Reverse & $5^{\prime}$-TGCAAATACAGCCACTACAACA-3' & $1163-1142$ \\
\hline \multirow[t]{2}{*}{ RAMP2 } & NM_001098860 & Forward & 5'- CAAGAAGGACTGGTGTGATTGG-3' & $359-381$ \\
\hline & & Reverse & 5'- AACTCTTCTGCACCCTITTCCA-3' & $443-422$ \\
\hline \multirow[t]{2}{*}{ RAMP3 } & NM_001083505 & Forward & 5'- TGGGTGGCTGCAATGAGAA-3' & $113-131$ \\
\hline & & Reverse & 5'- AGAGGTTGCACCACTTCCAGA-3' & 217-197 \\
\hline \multirow[t]{2}{*}{ GAPDH } & U85042 & Forward & 5'- ACCCAGAAGACTGTGGATGG-3' & $444-463$ \\
\hline & & Reverse & 5'-CAACAGACACGTTGGGAGTG-3' & $621-602$ \\
\hline
\end{tabular}



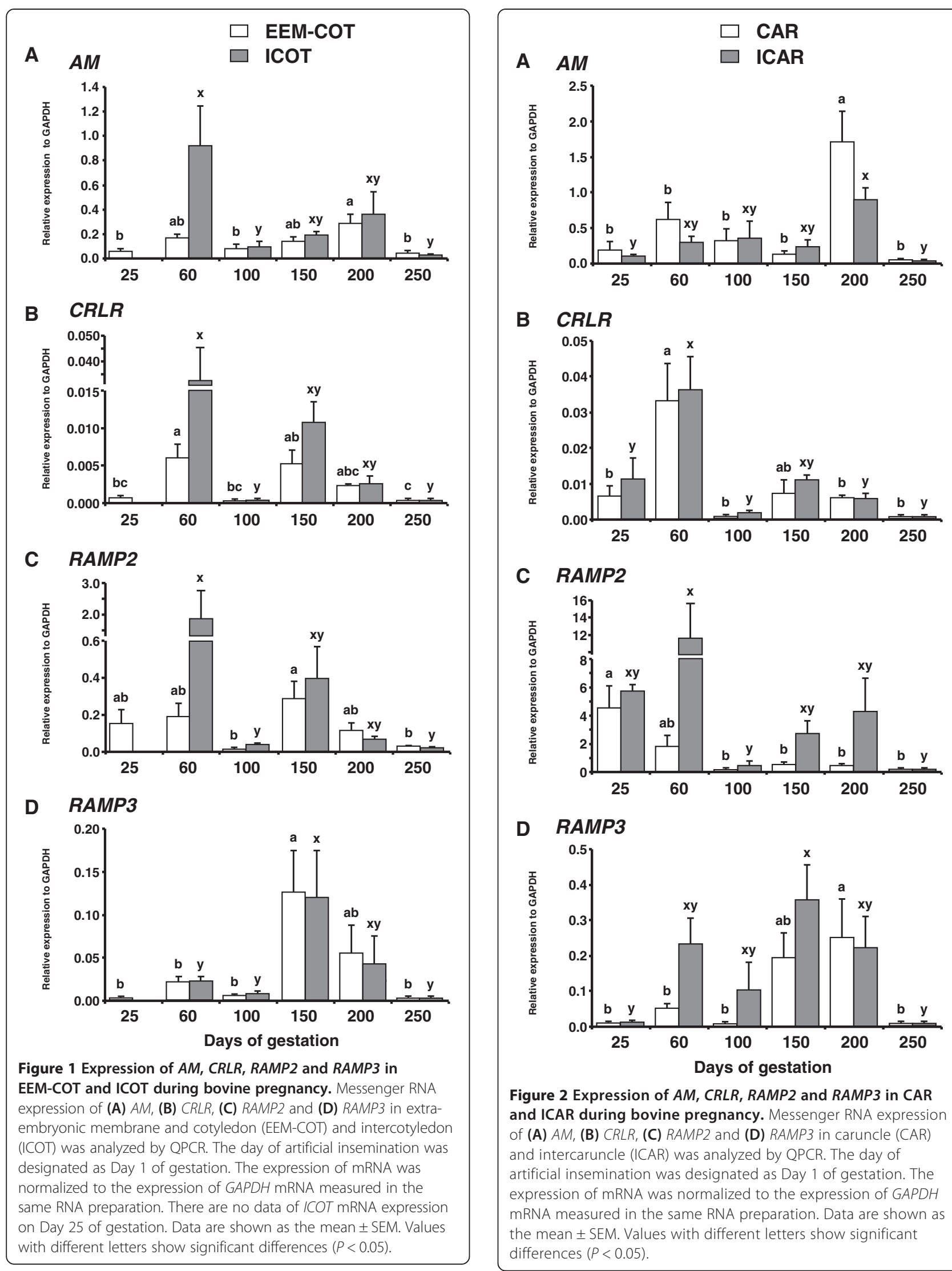

\section{B CRLR}

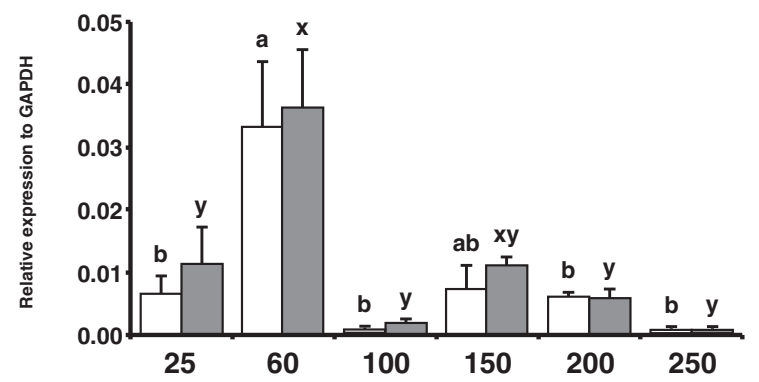

C RAMP2

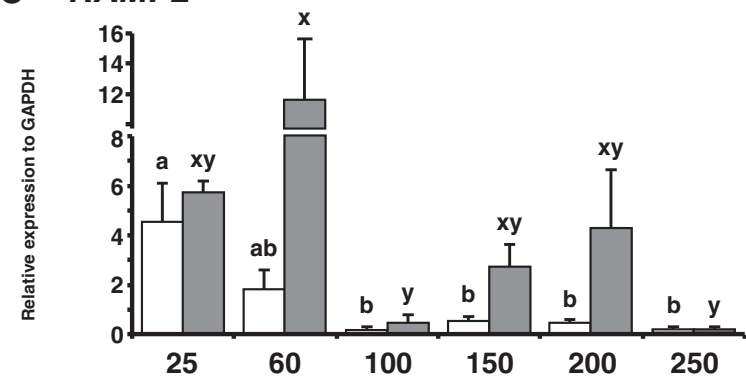

\section{RAMP3}

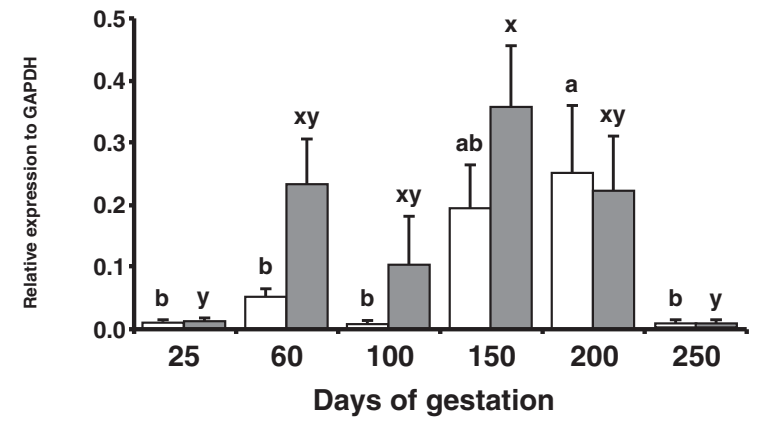

Figure 2 Expression of $A M, C R L R, R A M P 2$ and RAMP3 in CAR and ICAR during bovine pregnancy. Messenger RNA expression of (A) AM, (B) CRLR, (C) RAMP2 and (D) RAMP3 in caruncle (CAR) and intercaruncle (ICAR) was analyzed by QPCR. The day of artificial insemination was designated as Day 1 of gestation. The expression of mRNA was normalized to the expression of GAPDH mRNA measured in the same RNA preparation. Data are shown as the mean \pm SEM. Values with different letters show significant differences $(P<0.05)$. 
City, CA, USA) based on the bovine sequences. The primer sequences for each gene are provided in Table 1.

\section{In situ hybridization}

We investigated mRNA localization of $A M, C R L R, R A M P 2$ and $R A M P 3$ in the bovine placentome on Day 56, 150 and 230 of gestation and in the interplacental tissue on Day 56 of gestation. The details of procedures for preparation of Digoxigenin (DIG)-labeled anti-sense and sense cRNA probes and in situ hybridization using an automated Ventana HX System Discovery with a RiboMapKit and a BlueMapKit (Roche Diagnostics, Basel, Switzerland) were described previously by our colleague [24,25]. For in situ hybridization, paraffin-embedded samples were sectioned into 7 - $\mu \mathrm{m}$-thick sections. The hybridization signals were detected with a biotin-SP-IgG fraction monoclonal mouse anti-digoxin (200-062-156, Jackson Immuno Research Laboratories, West Grove, PA, USA). The hybridized slides were observed with a Leica DMRE HC microscope (Leica Microsystems, Wetzlar, Germany) and a Nikon Digital Sight DS-Fi1-L2 (Nikon, Tokyo, Japan).

\section{Immunohistochemistry}

Immunohistochemistry for AM, CRLR, RAMP2 and RAMP3 was performed in the bovine placentome on Day 56, 150 and 230 of gestation and in the interplacental tissue on Day 56 of gestation using the automated Ventana HX System Discovery with a DabMapKit (Roche) as described previously in detail by our laboratory [26]. The 7 - $\mu$ m-thick sections were incubated at room temperature with rabbit polyclonal anti-human AM antibody $(1.0 \mathrm{mg} / \mathrm{ml}$, T-4131, Peninsula Laboratories, San Carlos, CA, USA), rabbit polyclonal anti-human CRLR antibody $(1.0 \mathrm{mg} / \mathrm{ml}$, SP4082P, Acris Antibodies, Herford, Germany), rabbit polyclonal anti-human RAMP2 antibody $(0.3 \mathrm{mg} / \mathrm{ml}$, 13223-2-AP, Proteintech Group, Chicago, IL, USA) or rabbit polyclonal anti-human RAMP3 antibody $(0.5 \mathrm{mg} / \mathrm{ml}$, LS-B1833, LifeSpan BioSciences, Seattle, WA, USA) diluted 1:10 (anti-CRLR), 1:15 (anti-RAMP3), 1:80 (anti-AM) or 1:100 (anti-RAMP2) in Discovery Ab diluents (Roche) for $2 \mathrm{~h}$. The signals were detected using anti-rabbit IgG-Biotin conjugate (Sigma) diluted 1:500 for $1 \mathrm{~h}$. Negative controls were performed using normal rabbit IgG (5 mg/ml, GTX35035, GeneTex, Irvine, CA, USA) diluted at concentrations equivalent to the primary antibodies. The sections were observed with a Leica DMRE HC microscope (Leica Microsystems) and a Nikon Digital Sight DS-Fi1-L2 (Nikon).

\section{Statistical analysis}

The expression ratio of each gene to GAPDH mRNA was calculated to adjust for variations in the QPCR reaction. QPCR results were analyzed using one-way ANOVA followed by the Tukey-Kramer multiple comparison test.
Results are presented as the mean \pm SEM. Statistical significance is considered to be at $P<0.05$.

\section{Results}

mRNA expression of AM, CRLR, RAMP2 and RAMP3 in the bovine uteroplacental unit during pregnancy

Figure 1 shows mRNA expression of $A M, C R L R, R A M P 2$ and $R A M P 3$ in EEM-COT and ICOT during pregnancy. The mRNA expression level of $A M$ was higher on Day 200 than on Days 25, 100 and 250 in EEM-COT and higher on Day 60 than on Day 100 and 250 in ICOT (Figure 1A). CRLR mRNA expression level in EEM-COT was highest on Day 60 and decreased from Days 150 to 250 with a similar trend in ICOT (Figure 1B). The mRNA expression level of RAMP2 was higher on Day 150 in EEM-COT and on Day 60 in ICOT than on Day 100 and 250 (Figure 1C). RAMP3 mRNA expression in EEM-COT and ICOT was higher on Day 150 compared with Days 25, 60, 100 and 250 (Figure 1D).

Figure 2 shows mRNA expression of $A M, C R L R$, RAMP2 and RAMP3 in CAR and ICAR during pregnancy. $A M$ mRNA expression level was higher on Day 200 than on other gestation days and higher on Day 200 than on Days 25 and 250 in CAR and ICAR respectively (Figure 2A). The CRLR mRNA expression level in CAR and ICAR were higher on Day 60 than on Day 25, 100,

Table 2 Summary of mRNA expression profiles of $A M$, CRLR, RAMP2 and RAMP3 in bovine utero-placental tissues analyzed by QPCR

\begin{tabular}{|c|c|c|c|c|c|c|c|}
\hline \multirow[t]{2}{*}{ Genes } & \multirow[t]{2}{*}{ Tissues } & \multicolumn{6}{|c|}{ Days of gestation } \\
\hline & & 25 & 60 & 100 & 150 & 200 & 250 \\
\hline \multirow[t]{4}{*}{$A M$} & COT & + & + & + & + & ++ & + \\
\hline & ICOT & NA & +++ & + & + & ++ & + \\
\hline & CAR & + & ++ & + & + & +++ & + \\
\hline & ICAR & + & + & + & + & ++ & + \\
\hline \multirow[t]{4}{*}{$C R L R$} & COT & + & ++ & + & ++ & + & + \\
\hline & ICOT & NA & +++ & + & ++ & + & + \\
\hline & CAR & + & +++ & + & + & + & + \\
\hline & ICAR & ++ & +++ & + & ++ & + & + \\
\hline \multirow[t]{4}{*}{ RAMP2 } & COT & ++ & ++ & + & ++ & + & + \\
\hline & ICOT & NA & +++ & + & ++ & + & + \\
\hline & CAR & ++ & + & + & + & + & + \\
\hline & ICAR & ++ & +++ & + & ++ & ++ & + \\
\hline \multirow[t]{4}{*}{ RAMP3 } & COT & + & + & + & +++ & ++ & + \\
\hline & ICOT & NA & + & + & +++ & ++ & + \\
\hline & CAR & + & + & + & +++ & +++ & + \\
\hline & ICAR & + & +++ & ++ & +++ & +++ & + \\
\hline
\end{tabular}

+++ , strong expression; ++, moderate expression; +, slight expression; NA, sample not available. 


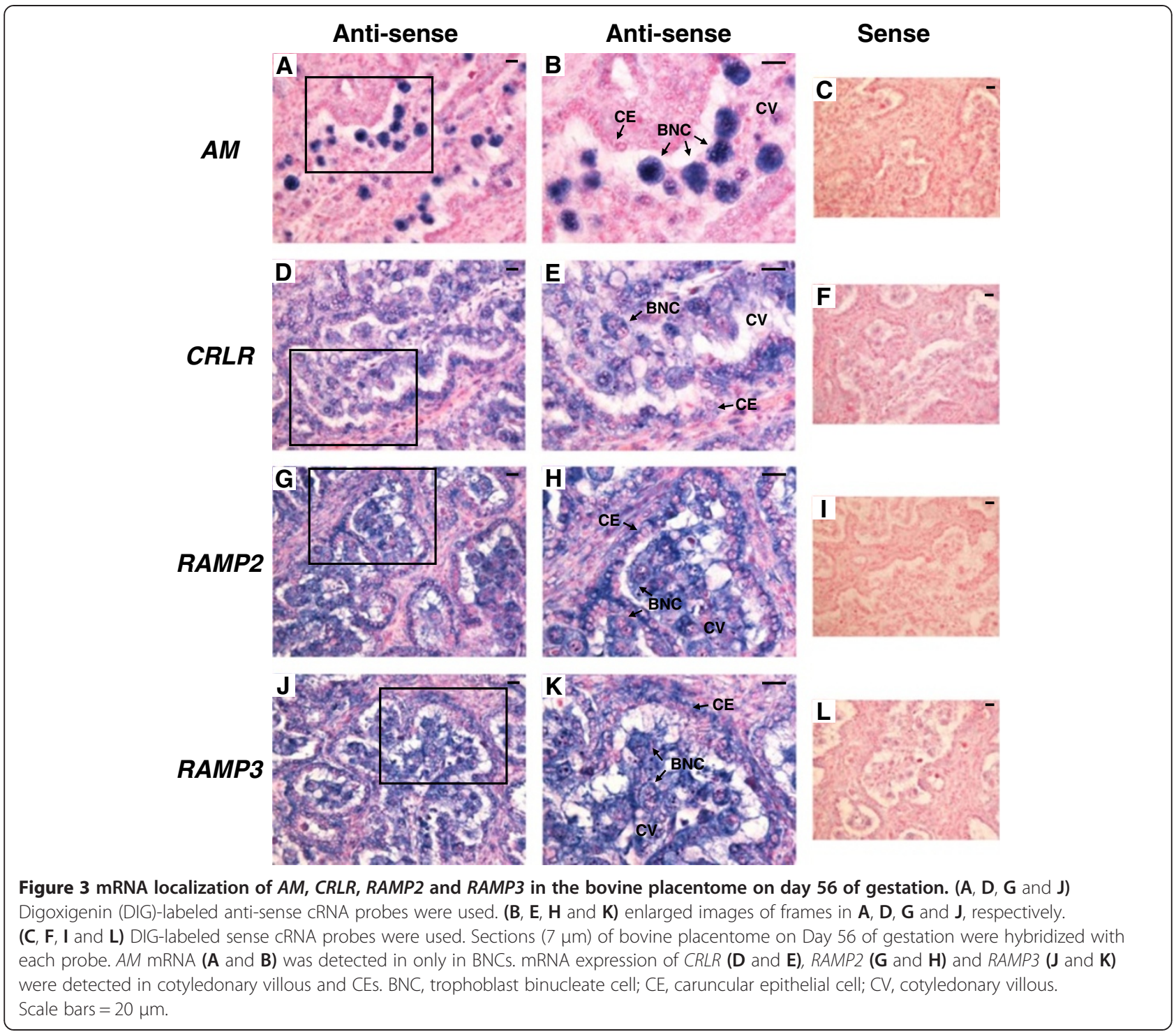

200 and 250 (Figure 2B). In ICAR, RAMP2 mRNA expression level was higher on Day 60 than on Day 100 and 250 and in CAR was highest on Day 25 (Figure 2C). RAMP3 mRNA expression in CAR increased from Day 100 to Day 200 then decreased on Day 250 (Figure 2D). In ICAR, RAMP3 mRNA expression level was higher on Day 150 than on Day 25 and 250 (Figure 2D). Table 2 shows the summary of mRNA expression profiles of $A M, C R L R$, $R A M P 2$ and RAMP3 in bovine uteroplacental tissues.

mRNA localization of AM, CRLR, RAMP2 and RAMP3 in bovine placentome on Day 56, 150 and 230 of gestation The results of in situ hybridization for AM, CRLR, RAMP2 and $R A M P 3$ in the bovine placentome on Day 56, 150 and 230 of gestation are shown in Figures 3, 4 and 5, respectively. Throughout gestation, $A M$ mRNA signal was detected only in BNCs (Figure 3A and B, Figure 4A and $\mathrm{B}$ and Figure $5 \mathrm{~A}$ and $\mathrm{B})$. CRLR mRNA was detected in both cotyledonary villous including BNCs and caruncular epithelial cells (Figure $3 \mathrm{D}$ and E, Figure 4D and E and Figure 5D and E). Both RAMP2 and RAMP3 mRNA were also found in both the cotyledonary villi, including BNCs and the caruncular epithelial cells (Figure 3G,H,J and $\mathrm{K}$, Figure 4G,H,J and $\mathrm{K}$ and Figure 5G,H,J and K). No significant signal was detected with any of the sense probes (Figure 3C,F,I and L, Figure 4C,F,I and L and Figure 5C,F,I and L).

mRNA localization of AM, CRLR, RAMP2 and RAMP3 in bovine interplacentomal tissues on Day 56 of gestation Figure 6 shows the results of in situ hybridization for $A M$, $C R L R, R A M P 2$ and $R A M P 3$ in the bovine interplacentomal 


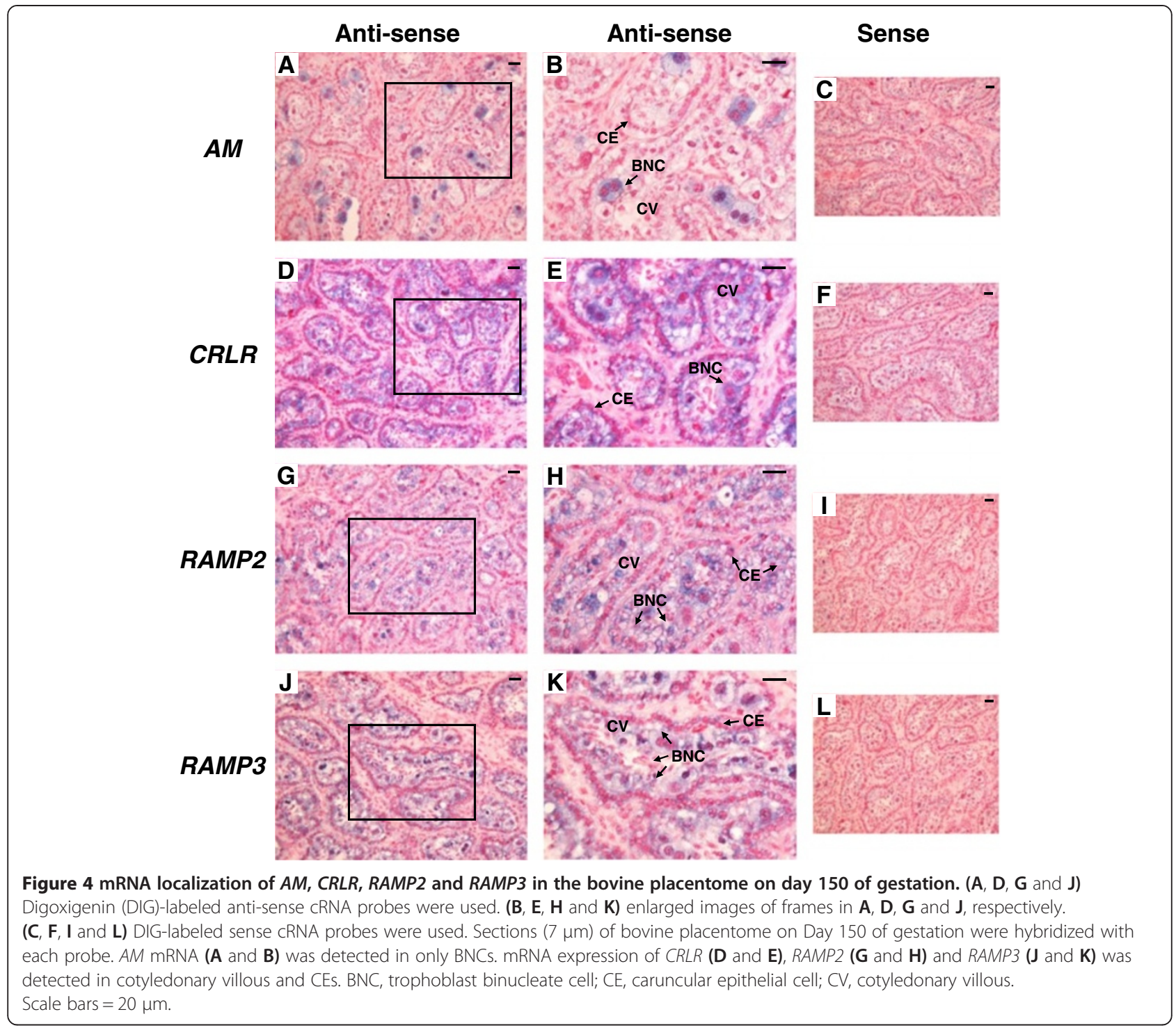

tissues on Day 56 of gestation. $A M$ mRNA was detected in BNCs of fetal membrane and a part of luminal epithelium (Figure 6A). It was also found in a small part of endothelial lineage of blood vessels and glandular epithelium of the endometrium (Figure 6B). CRLR, RAMP2 and RAMP3 mRNA were found in trophoblast cells including the BNCs, luminal epithelium, stroma under the epithelium, endothelial lineage of blood vessels and glandular epithelium (Figure 6D,E,G,H,J and K). No significant signal was detected with any of the sense probes (Figure 6C,F,I and L).

Protein localization of AM, CRLR, RAMP2 and RAMP3 in the bovine placentome on Day 56, 150 and 230 of gestation

The results of immunohistochemistry for $A M, C R L R$, $R A M P 2$ and $R A M P 3$ in the bovine placentome on Day
56, 150 and 230 of gestation are shown in Figures 7, 8 and 9, respectively. Throughout gestation, a distinct AM signal was found only in BNCs (Figure 7A and B, Figure 8A and $\mathrm{B}$ and Figure 9A and B). CRLR, RAMP2 and RAMP3 proteins were detected in cotyledonary villous, including BNCs, and caruncular epithelial cells (Figure 7D,E,G, $\mathrm{H}, \mathrm{J}$ and $\mathrm{K}$, Figure 8D,E,G,H,J and $\mathrm{K}$ and Figure 9D,E,G, $\mathrm{H}$,J and $\mathrm{K})$.

Protein localization of AM, CRLR, RAMP2 and RAMP3 in the bovine interplacentomal tissues on Day 56 of gestation

Figure 10 shows the results of in situ hybridization for $A M, C R L R, R A M P 2$ and RAMP3 in the bovine interplacentomal tissues on Day 56 of gestation. Immunoreactive AM protein was detected in BNCs of fetal membrane and a part of luminal epithelium (Figure 6A). 


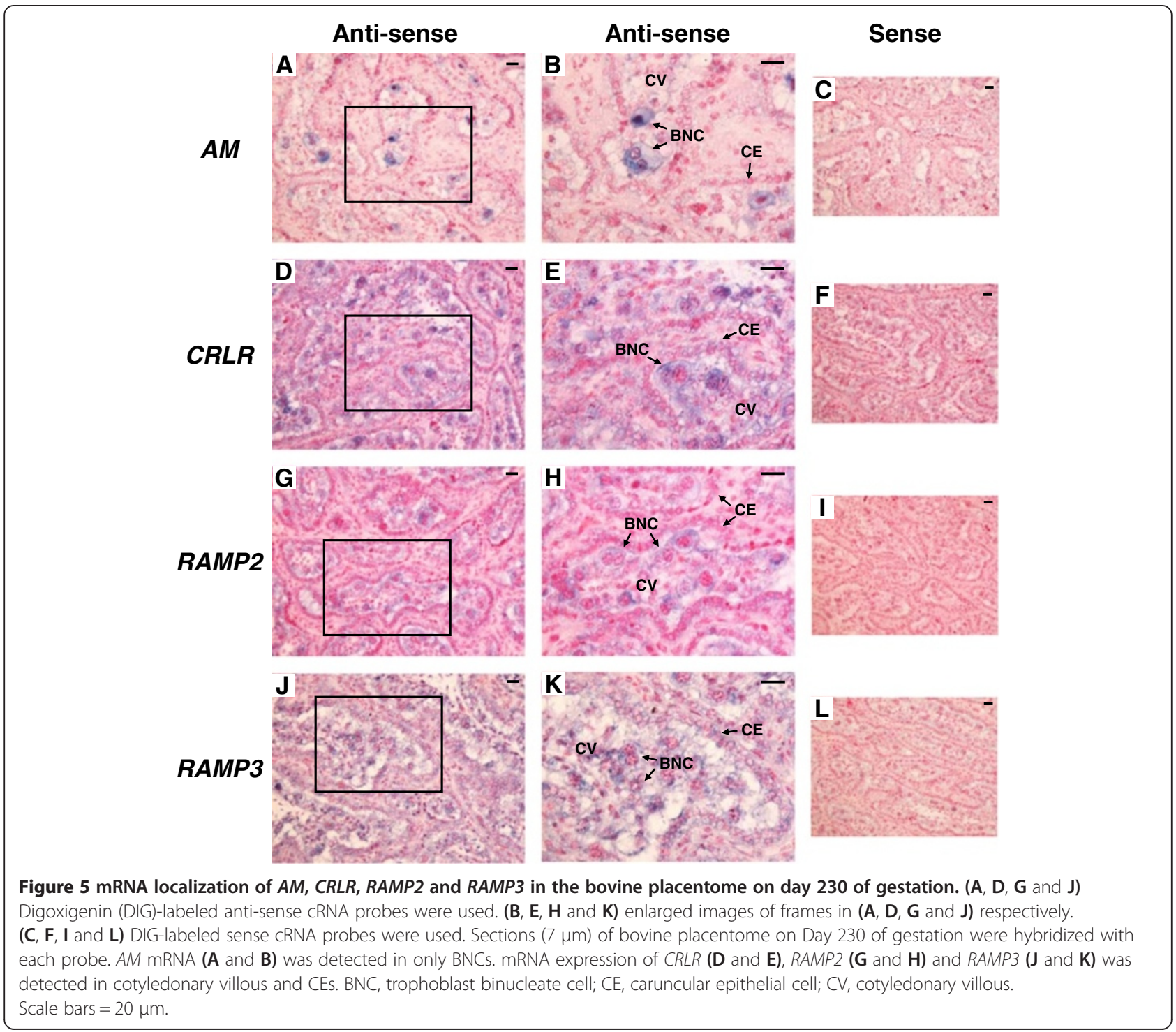

A weak AM staining was found in endothelial lineage of blood vessels and glandular epithelium of the endometrium (Figure 10B). CRLR, RAMP2 and RAMP3 positive staining were found in trophoblast cells, luminal epithelia, stroma under the epithelium, endothelial lineage of blood vessels and glandular epithelium (Figure 10D,E,G,H,J and K).

\section{Discussion}

This is the first study to show that AM and its receptors are expressed in the bovine uteroplacental unit and that their mRNA expression pattern changes considerably during the course of pregnancy. We also demonstrated for the first time that AM mRNA and protein in the bovine placentome were detected only in BNCs, whereas those of CRLR, RAMP2 and RAMP3 were localized in trophoblast cells, including the BNCs, and caruncular epithelial cells. In interplacentomal tissues, mRNA and protein of AM were mainly detected in BNCs of fetal membrane and CRLR, RAMP2 and RAMP3 were found in fetal membrane, luminal epithelium, stroma under the epithelium, endothelial lineage of blood vessels and glandular epithelium. The results of in situ hybridization and immunohistochemistry were almost match, suggesting transcripted and translated AM, CRLR and RAMP2 proteins continue to localize in the same cells in bovine utero-placenta throughout gestation period. It seems that locally produced AM is an important factor in the regulation of bovine placental function, as has been previously suggested in human and mouse studies [10].

In this study, the mRNA expression profiles of $A M$, CRLR, RAMP2 and RAMP3 in the uteroplacental unit 


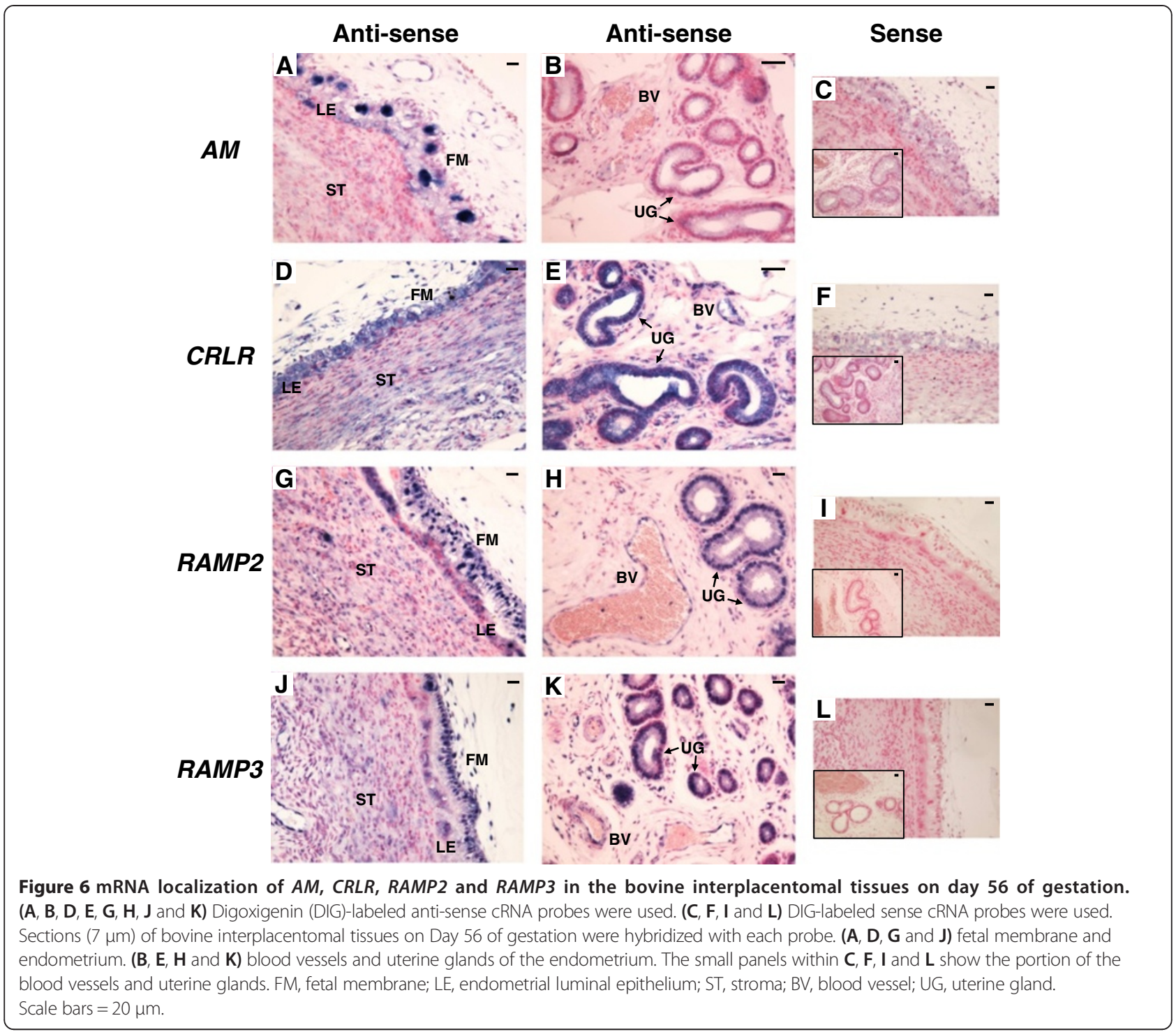

were summarized as follows: $A M$ mRNA was expressed in all tissues from the beginning of placentation to mid gestation transition (Days 60-200). CRLR mRNA was lowest expression but most abundant in maternal tissue at the beginning of placentation. RAMP2 mRNA was also most abundant in maternal tissue at the beginning of placentation whereas RAMP3 mRNA was present in the fetal and maternal tissues more abundantly mid to late gestation. $A M$ mRNA in ICOT and CRLR and RAMP2 mRNA in all regions were highly expressed on Day 60 of gestation. $\mathrm{AM}$ promotes the migration and invasion of endothelial cells through CRLR/RAMP2 and CRLR/RAMP3 receptors [27]. Homozygous knockout of RAMP2 causes embryonic death in the mouse due to severe vascular abnormality, suggesting that the CRLR/RAMP2 receptor is required for angiogenesis [28]. Both maternal and fetal vasculature of the bovine placentome at the third and fourth month of gestation are still immature and consist only of simple capillary loops [2]. Although changes in mRNA expression of two of the primary angiogenic factors, fibroblast growth factor (FGF) and vascular endothelial growth factor (VEGF), have been reported in the bovine placentome during pregnancy, VEGF and its receptors on both the fetal and maternal side of the placentome increase after Day 80 of gestation and FGF1 and FGF type 2 receptor in the total placentome increase from around Day 80 until Day 200 of gestation [5]. Therefore, increased CRLR and $R A M P 2$ mRNA expression in the bovine uteroplacental unit at Day 60 of gestation may be involved in the stimulation of angiogenesis at an early stage of placentation before the increase in VEGF and FGF. 


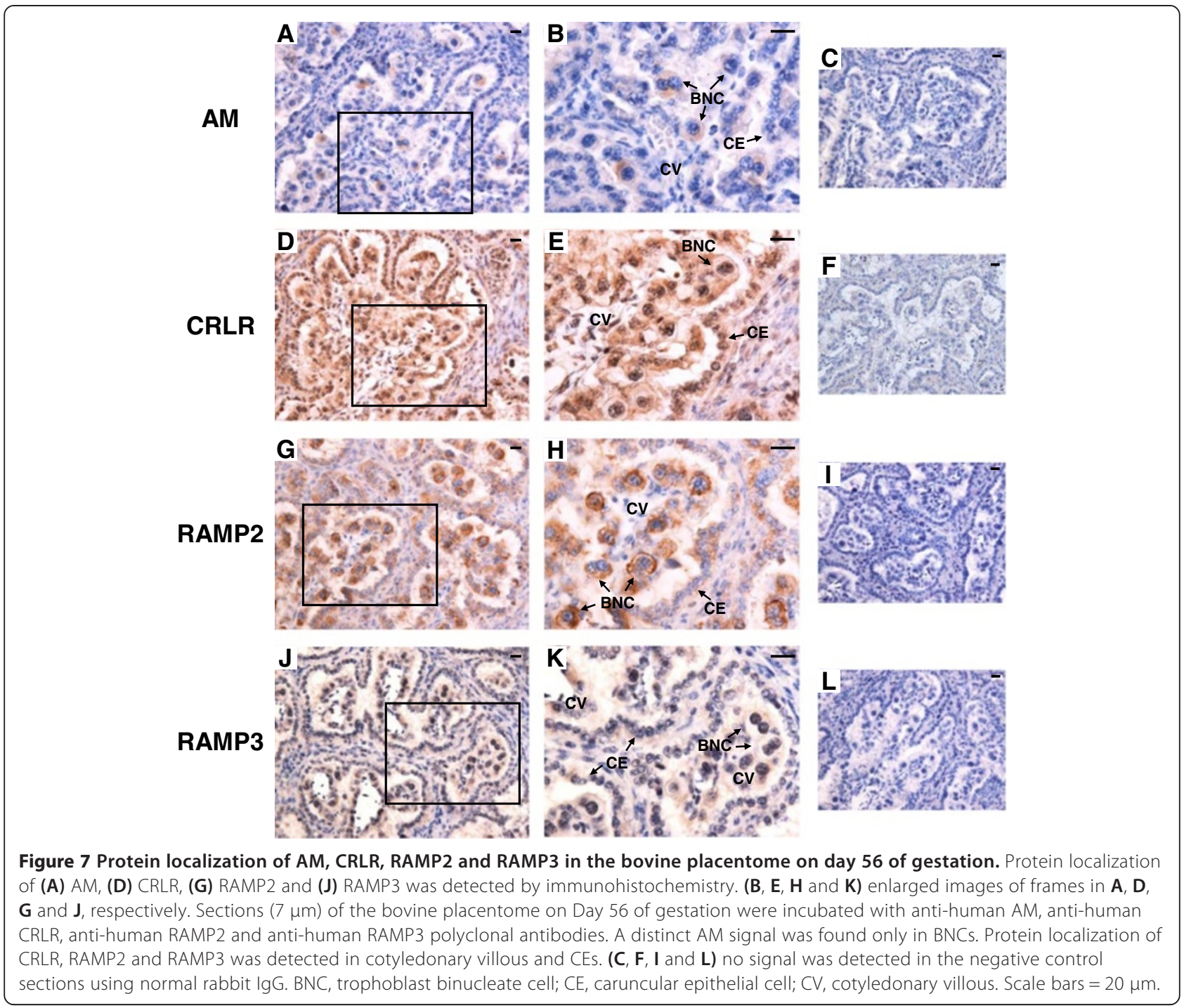

$A M$ and RAMP3 mRNA were highly expressed in EEM-COT, CAR and ICAR from Day 150 to Day 200 as compared with early or mid-gestation. The AM signal during this period is likely to act via the CRLR/RAMP3 receptor. The weight and length of bovine placentomes increase exponentially and their growth rates peak at Day 200 of gestation [29]. In addition, bovine uterine artery blood flow increases linearly throughout gestation, suggesting an increase in blood supply to the placenta [30]. In the bovine uteroplacental unit, gene expression of several major vasoactive substances such as endothelin-1 system, angiotensin II system and endothelial nitric oxide (NO) synthase increase during the mid-gestation period $[3,4,6]$. The AM-induced vasodilatation is partially mediated through NO release [31]. Locally produced AM in bovine placenta may regulate the vascular tonus in response to increasing blood supply by coordinating with other vasoactive substances to support placental development and fetomaternal exchange. Treatment with AM antagonist during late gestation in the rat causes necrosis in the decidua and labyrinthine trophoblast resulting in decreased placental and fetal weight and an increased incidence of fetal reabsorption [20]. One possible reason for these abnormalities is deficient vascular development in the placenta [20]. Therefore, it is plausible that AM plays certain roles in not only functional, but also morphological regulation of uteroplacental vasculature during mid to late gestation in bovine.

We revealed by in situ hybridization and immunohistochemistry that the BNC is the primary source of AM production in the bovine placenta. In addition, CRLR and RAMPs are localized in same cell types within bovine uteroplacental tissues. This suggests that CRLR 


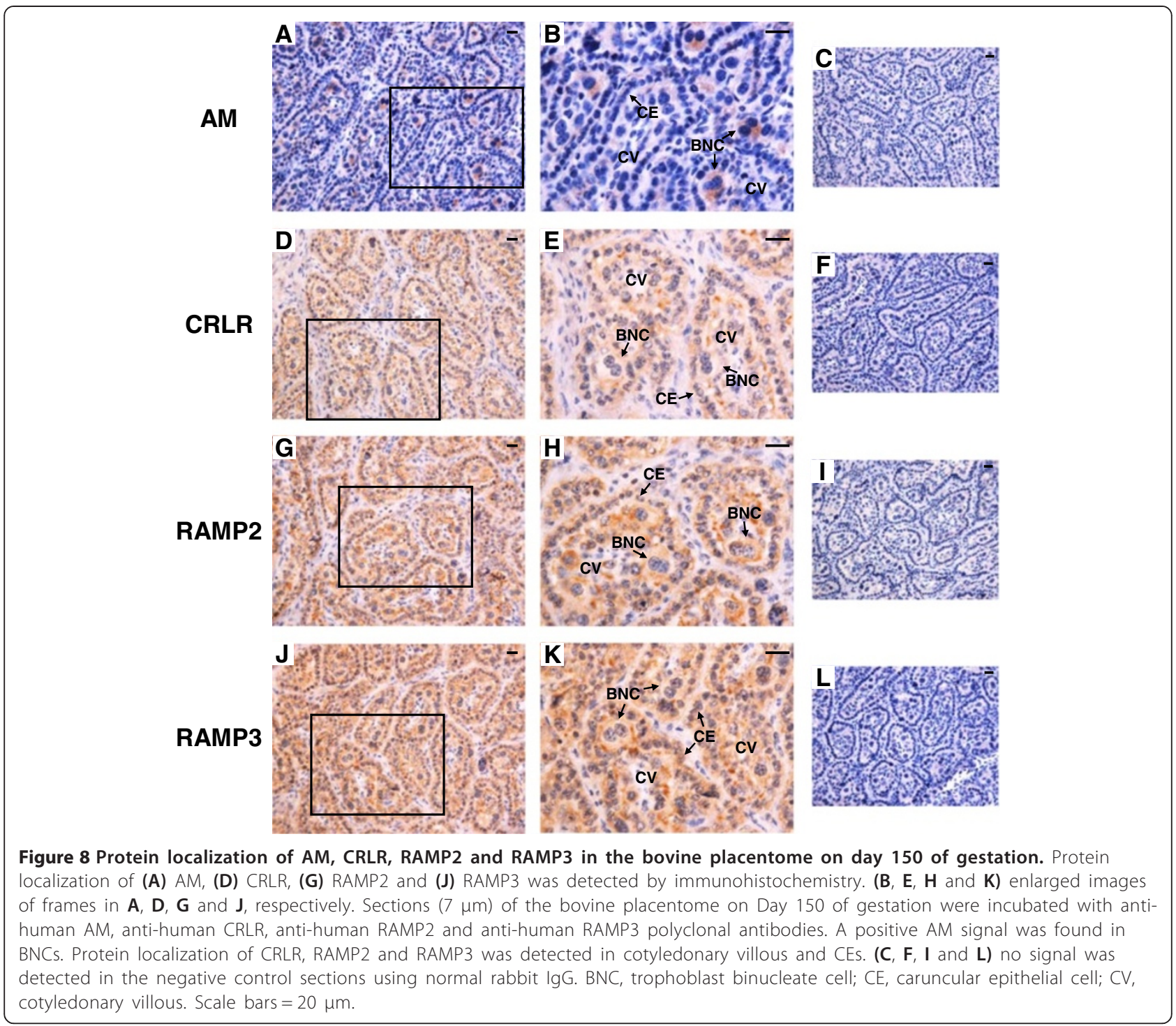

and RAMPs form receptor complex and exist as functional AM receptors in these cells. The secreted AM may act on fetal and maternal placental cells through an autocrine/paracrine mechanism. This finding is in agreement with previous report that $A M$ mRNA is most highly expressed in trophoblast giant cells in the mouse placenta [18]. The bovine BNC secretes various placental-specific molecules such as placental lactogen (PL), pregnancy-associated glycoproteins (PAGs) and prolactin-related proteins (PRPs) in COT and ICOT, which play a crucial role in the regulation of placentation, maintenance of pregnancy and stimulation of fetal growth [32]. Some of these molecules show a similar temporal expression profile with AM during pregnancy, that is the mRNA expression of PRP1 in ICOT peaks at Day 60 of gestation and PL, PAG1,
PAG9 and PRP-VII in COT begins to increase at mid gestation $[24,33]$. Thus, we speculate that AM may be involved in the regulation of secretory function of the $\mathrm{BNC}$ to interact with these placental-specific molecules in both placentome and interplacentomal regions. In addition, it has been reported that AM affects the secretory activities of endocrine organs including the pituitary gland, adrenal cortex and ovary [34-38]. In rats, AM inhibited FSH-induced estradiol secretion in follicles and also suppressed eCG-stimulated progesterone release in corpus luteum [37]. In vitro treatment of preantral follicular culture with AM increased estradiol production [38]. The regulation of progesterone production by AM in corpus luteum in culture was pregnancy-stage dependent, inhibitory at early and late pregnancy but stimulatory at mid pregnancy [38]. 


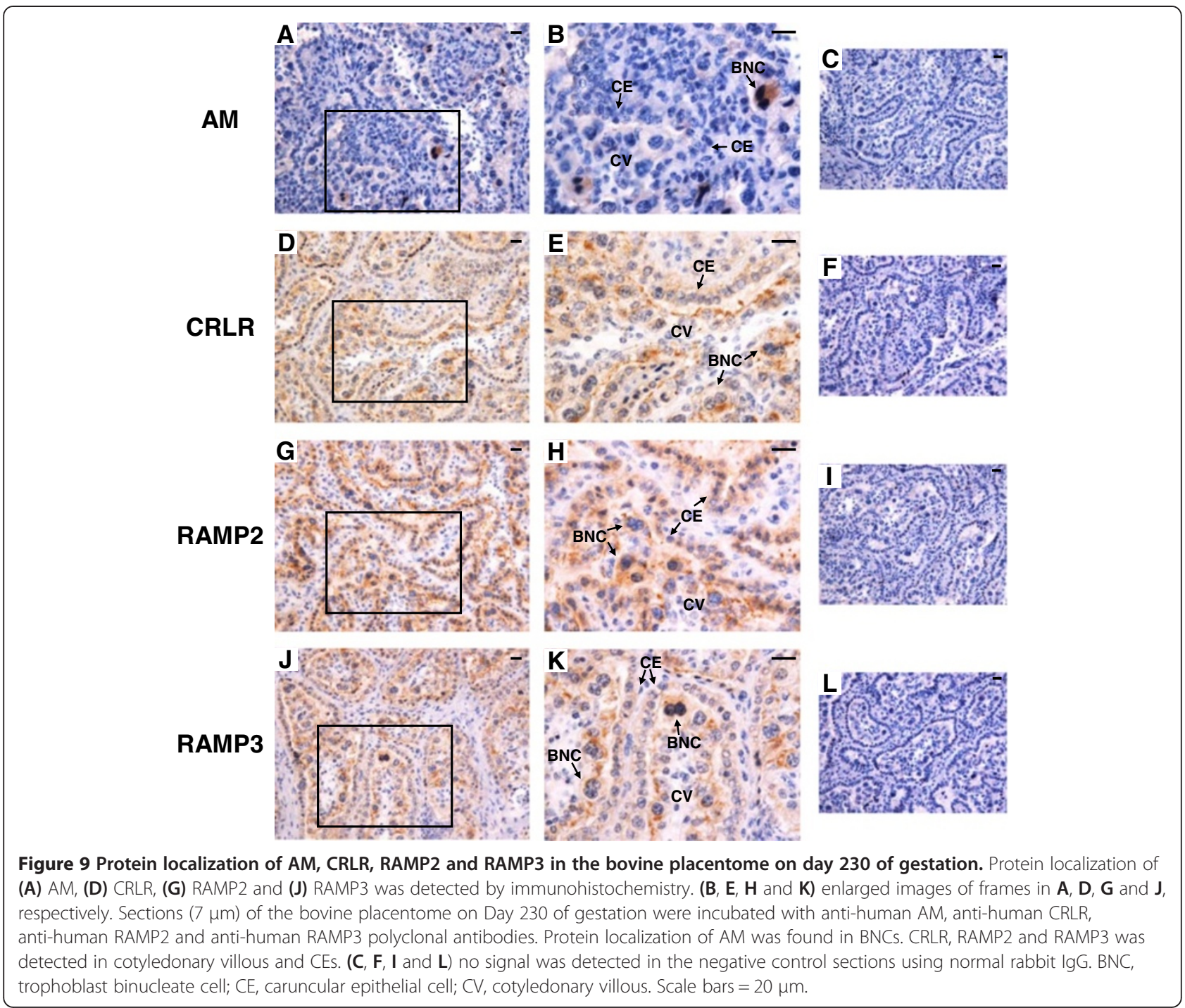

Since the utero-placenta is a major source of estrogen secretion during bovine pregnancy $[39,40]$, AM may act as an important regulator in steroids production to maintain pregnancy.

Adrenomedullin enhances both cell invasion and proliferation via CRLR and RAMP2 in human choriocarcinoma cells [41]. In mice, invasive trophoblast giant cells show dramatic upregulation of AM genes compared with undifferentiated trophectoderm cells, indicating the involvement of AM in trophoblast invasion and guidance of developing placental tissue [22]. The bovine $\mathrm{BNC}$ is known to appear around Day 20 of gestation and migrate and fuse with endometrial epithelium from the trophoblast epithelium throughout gestation [1]. AM, CRLR and RAMP2 mRNA were expressed in BNCs throughout gestation, suggesting that AM may also have a regulatory effect on migration, proliferation and/or turnover of the BNC itself during bovine placental development.

Treatment with AM antagonist during early rat pregnancy causes severely retarded placental development and restricted fetal growth through apoptosis of the placenta and uterus [21]. This activation of apoptosis is due to decreased antiapoptotic protein $\mathrm{Bcl}-2$ levels and increased mitochondrial proapoptotic Bcl2-associated $\mathrm{X}$ protein (Bax) levels with a decrease in cytochrome $\mathrm{C}$ levels in both the placenta and uterus [21]. In the bovine placenta, mRNA expression of $\mathrm{Bcl}-2$ related antiapoptotic protein $B c l 2 A 1$ in bovine COT is higher on Day 60 and 150 of gestation than in EEM on Day 28 of gestation and the expression ratio between Bcl2A1 and BAX is highest on Day 60 of gestation [25]. In addition, the mean number of apoptotic cells in bovine fetal and maternal placenta increases significantly from 


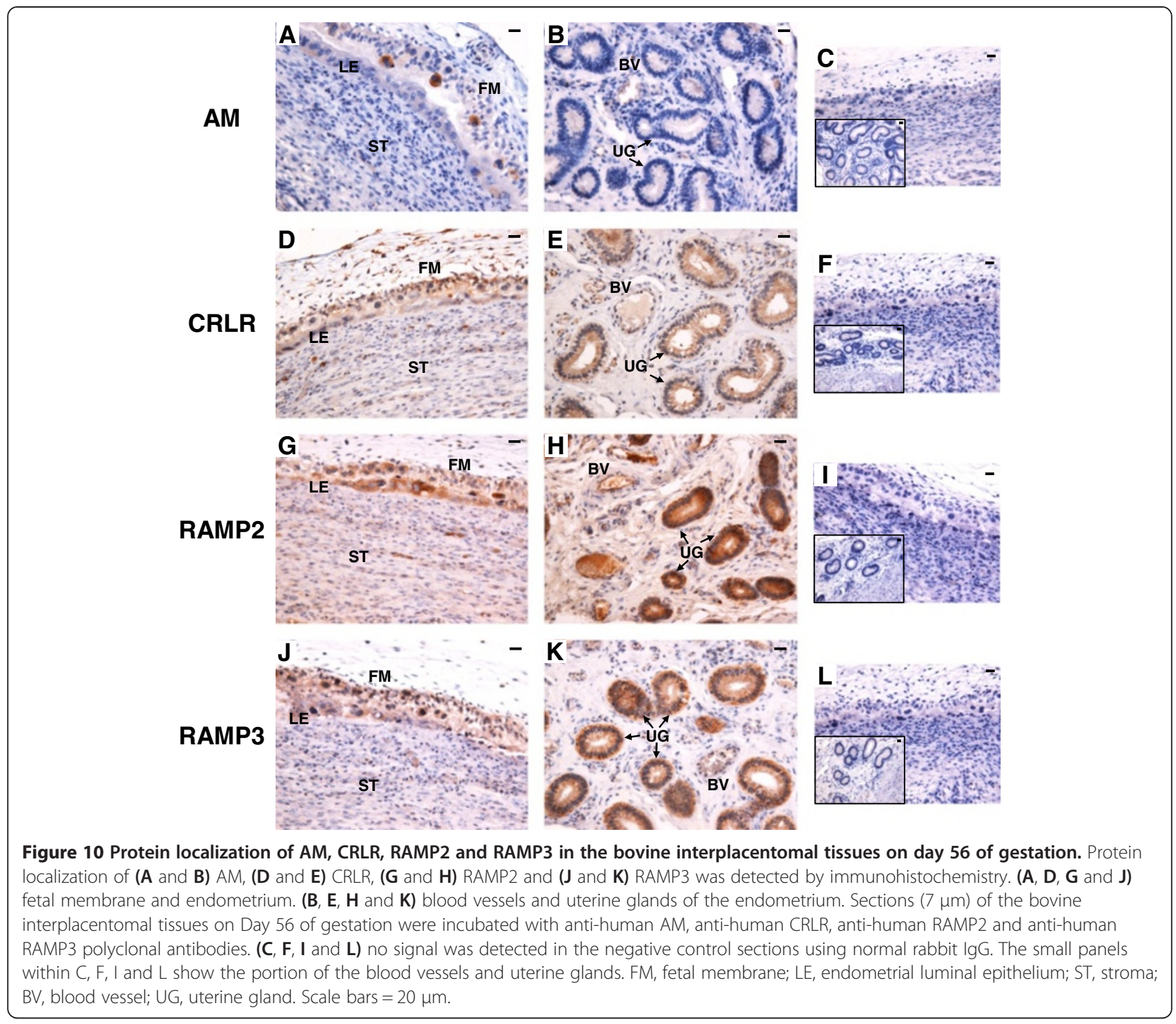

the first to the third trimester [42]. Both CRLR and RAMP2 mRNA in the bovine placenta may also be involved in regulation of local apoptosis for adequate placentation.

In the present study, AM, CRLR, RAMP2 and RAMP3 mRNA and protein were also found in interplacentomal endometrium (ICAR) by both QPCR and histological studies. It has been reported that uterine secretions are essential for survival and development of the embryo and associated extraembryonic membranes [43] and uterine artery blood flow increase throughout bovine pregnancy [30]. The AM system may affect the regulation of cellular remodeling of luminal epithelium, angiogenesis, vascular permeability and uterine gland function via $\mathrm{AM}$ receptors within endometrium. Further studies are required to determine the functional role of AM system in bovine placental development and maintenance of pregnancy.

\section{Conclusions}

In conclusion, our results indicate that the AM system in the bovine uteroplacental unit may be activated at the beginning of placentation and transition from the mid to late gestation period. Locally produced AM in the BNC may play a crucial role in the regulation of placental vascular and cellular functions by autocrine/paracrine action during pregnancy.

\section{Competing interests}

The authors declare that they have no competing interests.

\section{Authors' contributions}

$\mathrm{KGH}$ participated in the design of the study, collected the materials, carried out all experiments and drafted the manuscript. $\mathrm{MH}$ was responsible for all animal care, collected the materials and helped to carry out all experiments. RS collected the materials and helped to carry out QPCR and in situ hybridization. TT supervised the study, collected the materials and helped to draft the manuscript. All authors read and approved the final manuscript. 


\section{Acknowledgements}

This study was supported by a Grant-in-Aid for Young Scientist (B) from the Ministry of Education, Culture, Sports, Science and Technology of Japan (23780284), Research Program on Innovative Technologies for Animal Breeding, Reproduction, and Vaccine Development (REP-1001) from the Ministry of Agriculture, Forestry and Fisheries of Japan and the NIAS Strategic Research Fund. This manuscript was reviewed by a professional copyediting service (SciRevision, Kagawa, Japan) prior to submission.

\section{Author details}

'Animal Physiology Research Unit, Division of Animal Science, National Institute of Agrobiological Sciences, Tsukuba 305-8602, Japan. ${ }^{2}$ Animal Development and Differentiation Research Unit, Division of Animal Science, National Institute of Agrobiological Sciences, Tsukuba 305-8602, Japan. ${ }^{3}$ Present address: Cooperative Department of Veterinary Medicine, Faculty of Agriculture, Iwate University, Morioka 020-8550, Japan.

Received: 5 February 2013 Accepted: 10 July 2013

Published: 13 July 2013

\section{References}

1. Wooding FB, Wathes DC: Binucleate cell migration in the bovine placentome. J Reprod Fertil 1980, 59:425-430.

2. Pfarrer C, Ebert B, Miglino MA, Klisch K, Leiser R: The three-dimensional feto-maternal vascular interrelationship during early bovine placental development: a scanning electron microscopical study. J Anat 2001, 198:591-602.

3. Schauser KH, Nielsen AH, Winther H, Dantzer V, Poulsen K: Autoradiographic localization and characterization of angiotensin II receptors in the bovine placenta and fetal membranes. Biol Reprod 1998, 59:684-692.

4. Schauser KH, Nielsen AH, Dantzer V, Poulsen K: Angiotensin-converting enzyme activity in the bovine uteroplacental unit changes in relation to the cycle and pregnancy. Placenta 2001, 22:852-862.

5. Pfarrer CD, Ruziwa SD, Winther H, Callesen H, Leiser R, Schams D, Dantzer V: Localization of vascular endothelial growth factor (VEGF) and its receptors VEGFR-1 and VEGFR-2 in bovine placentomes from implantation until term. Placenta 2006, 27:889-898.

6. Hayashi KG, Hosoe M, Takahashi T: Placental expression and localization of endothelin-1 system and nitric oxide synthases during bovine pregnancy. Anim Reprod Sci 2012, 134:150-157.

7. Kitamura K, Kangawa K, Kawamoto M, Ichiki Y, Nakamura S, Matsuo H, Eto T: Adrenomedullin: a novel hypotensive peptide isolated from human pheochromocytoma. Biochem Biophys Res Commun 1993, 192:553-560.

8. Hinson JP, Kapas S, Smith DM: Adrenomedullin, a multifunctional regulatory peptide. Endocr Rev 2000, 21:138-167.

9. McLatchie LM, Fraser NJ, Main MJ, Wise A, Brown J, Thompson N, Solari R, Lee MG, Foord SM: RAMPs regulate the transport and ligand specificity of the calcitonin-receptor-like receptor. Nature 1998, 393:333-339.

10. Wilson C, Nikitenko LL, Sargent IL, Rees MC: Adrenomedullin: multiple functions in human pregnancy. Angiogenesis 2004, 7:203-212.

11. Beltowski J, Jamroz A: Adrenomedullin-what do we know 10 years since its discovery? Pol J Pharmacol 2004, 56:5-27.

12. Kuwasako K, Kitamura K, Nagata S, Hikosaka T, Takei Y, Kato J: Shared and separate functions of the RAMP-based adrenomedullin receptors. Peptides 2011, 32:1540-1550.

13. Marinoni E, Di lorio R, Letizia C, Villaccio B, Scucchi L, Cosmi EV: Immunoreactive adrenomedullin in human fetoplacental tissues. Am J Obstet Gynecol 1998, 179:784-787.

14. Kanenishi K, Kuwabara H, Ueno M, Sakamoto H, Hata T: Immunohistochemical adrenomedullin expression is decreased in the placenta from pregnancies with pre-eclampsia. Pathol Int 2000, 50:536-540.

15. Moriyama T, Otani T, Maruo T: Expression of adrenomedullin by human placental cytotrophoblasts and choriocarcinoma JAr cells. J Clin Endocrinol Metab 2001, 86:3958-3961.

16. Nikitenko LL, Brown NS, Smith DM, MacKenzie IZ, Bicknell R, Rees MC: Differential and cell-specific expression of calcitonin receptor-like receptor and receptor activity modifying proteins in the human uterus. Mol Hum Reprod 2001, 7:655-664.

17. Dong YL, Reddy DM, Green KE, Chauhan MS, Wang HQ, Nagamani M, Hankins GD, Yallampalli C: Calcitonin gene-related peptide (CALCA) is a proangiogenic growth factor in the human placental development. Biol Reprod 2007, 76:892-899.

18. Yotsumoto S, Shimada T, Cui CY, Nakashima H, Fujiwara H, Ko MS: Expression of adrenomedullin, a hypotensive peptide, in the trophoblast giant cells at the embryo implantation site in mouse. Dev Biol 1998, 203:264-275.

19. Li L, Tang F, WS O: Coexpression of adrenomedullin and its receptor component proteins in the reproductive system of the rat during gestation. Reprod Biol Endocrinol 2010, 8:130

20. Witlin AG, Li ZY, Wimalawansa SJ, Grady JJ, Grafe MR, Yallampalli C: Placental and fetal growth and development in late rat gestation is dependent on adrenomedullin. Biol Reprod 2002, 67:1025-1031.

21. Penchalaneni J, Wimalawansa SJ, Yallampalli C: Adrenomedullin antagonist treatment during early gestation in rats causes fetoplacental growth restriction through apoptosis. Biol Reprod 2004, 71:1475-1483.

22. Li M, Yee D, Magnuson TR, Smithies O, Caron KM: Reduced maternal expression of adrenomedullin disrupts fertility, placentation, and fetal growth in mice. J Clin Invest 2006, 116:2653-2662.

23. Ushizawa K, Takahashi T, Hosoe M, Ishiwata H, Kaneyama K, Kizaki K, Hashizume K: Global gene expression analysis and regulation of the principal genes expressed in bovine placenta in relation to the transcription factor AP-2 family. Reprod Biol Endocrinol 2007, 5:17.

24. Ushizawa K, Kaneyama K, Takahashi T, Tokunaga T, Tsunoda Y, Hashizume K: Cloning and expression of a new member of prolactin-related protein in bovine placenta: bovine prolactin-related protein-VII. Biochem Biophys Res Commun 2005, 326:435-441.

25. Ushizawa K, Takahashi T, Kaneyama K, Hosoe M, Hashizume K: Cloning of the bovine antiapoptotic regulator, BCL2-related protein $\mathrm{A} 1$, and its expression in trophoblastic binucleate cells of bovine placenta. Biol Reprod 2006, 74:344-351.

26. Ushizawa K, Takahashi T, Hosoe M, Kizaki K, Hashizume K: Characterization and expression analysis of SOLD1, a novel member of the retrotransposon-derived Ly-6 superfamily, in bovine placental villi. PLoS One 2009, 4:e5814.

27. Fernandez-Sauze S, Delfino C, Mabrouk K, Dussert C, Chinot O, Martin PM, Grisoli $F$, Ouafik L, Boudouresque F: Effects of adrenomedullin on endothelial cells in the multistep process of angiogenesis: involvement of CRLR/RAMP2 and CRLR/RAMP3 receptors. Int I Cancer 2004, 108:797-804

28. Ichikawa-Shindo Y, Sakurai T, Kamiyoshi A, Kawate H, linuma N, Yoshizawa T, Koyama T, Fukuchi J, limuro S, Moriyama N, et al: The GPCR modulator protein RAMP2 is essential for angiogenesis and vascular integrity. J Clin Invest 2008, 118:29-39.

29. Laven RA, Peters AR: Gross morphometry of the bovine placentome during gestation. Reprod Domest Anim 2001, 36:289-296.

30. Panarace M, Garnil C, Marfil M, Jauregui G, Lagioia J, Luther E, Medina M: Transrectal Doppler sonography for evaluation of uterine blood flow throughout pregnancy in 13 cows. Theriogenology 2006, 66:2113-2119.

31. Hirata Y, Hayakawa H, Suzuki Y, Suzuki E, Ikenouchi H, Kohmoto O, Kimura K, Kitamura K, Eto T, Kangawa K, et al: Mechanisms of adrenomedullin-induced vasodilation in the rat kidney. Hypertension 1995, 25:790-795.

32. Hashizume K, Ushizawa K, Patel OV, Kizaki K, Imai K, Yamada O, Nakano H, Takahashi T: Gene expression and maintenance of pregnancy in bovine: roles of trophoblastic binucleate cell-specific molecules. Reprod Fertil Dev 2007, 19:79-90.

33. Patel OV, Yamada O, Kizaki K, Todoroki J, Takahashi T, Imai K, Schuler LA, Hashizume K: Temporospatial expression of placental lactogen and prolactin-related protein-1 genes in the bovine placenta and uterus during pregnancy. Mol Reprod Dev 2004, 69:146-152.

34. Samson WK, Murphy T, Schell DA: A novel vasoactive peptide, adrenomedullin, inhibits pituitary adrenocorticotropin release. Endocrinology 1995, 136:2349-2352.

35. Hinson JP, Thomson LM, Kapas S: Adrenomedullin and CGRP receptors mediate different effects in the rat adrenal cortex. Endocr Res 1998, 24:725-728.

36. Kapas S, Martinez A, Cuttitta F, Hinson JP: Local production and action of adrenomedullin in the rat adrenal zona glomerulosa. J Endocrinol 1998, 156:477-484.

37. Li YY, Li L, Hwang IS, Tang F: O WS: Coexpression of adrenomedullin and its receptors in the reproductive system of the rat: effects on steroid secretion in rat ovary. Biol Reprod 2008, 79:200-208. 
38. Li L, WS O, Tang F: Adrenomedullin in rat follicles and corpora lutea: expression, functions and interaction with endothelin-1. Reprod Biol Endocrinol 2011, 9:111.

39. Schuler G, Greven H, Kowalewski MP, Döring B, Ozalp GR, Hoffmann B: Placental steroids in cattle: hormones, placental growth factors or by-products of trophoblast giant cell differentiation? Exp Clin Endocrinol Diabetes 2008, 116:429-436.

40. Verduzco A, Fecteau G, Lefebvre R, Smith LC, Murphy BD: Expression of steroidogenic proteins in bovine placenta during the first half of gestation. Reprod Fertil Dev 2012, 24:392-404.

41. Zhang X, Green KE, Yallampalli C, Dong YL: Adrenomedullin enhances invasion by trophoblast cell lines. Biol Reprod 2005, 73:619-626.

42. Boos A, Janssen V, Mulling C: Proliferation and apoptosis in bovine placentomes during pregnancy and around induced and spontaneous parturition as well as in cows retaining the fetal membranes. Reproduction 2003, 126:469-480.

43. Gray CA, Bartol FF, Tarleton BJ, Wiley AA, Johnson GA, Bazer FW, Spencer TE: Developmental biology of uterine glands. Biol Reprod 2001, 65:1311-1323.

doi:10.1186/1477-7827-11-62

Cite this article as: Hayashi et al:: Temporo-spatial expression of

adrenomedullin and its receptors in the bovine placenta. Reproductive

Biology and Endocrinology 2013 11:62.

\section{Submit your next manuscript to BioMed Central and take full advantage of:}

- Convenient online submission

- Thorough peer review

- No space constraints or color figure charges

- Immediate publication on acceptance

- Inclusion in PubMed, CAS, Scopus and Google Scholar

- Research which is freely available for redistribution 